\title{
Analisa dan Implementasi Sistem Keamanan Jaringan Komputer dengan Iptables sebagai Firewall Menggunakan Metode Port Knocking
}

\author{
Irwan Sembiring, Indrastanti R. Widiasari, Sujiwo Danu Prasetyo \\ Fakultas Teknologi Informasi \\ Universitas Kristen Satya Wacana \\ Jl. Diponegoro 52-60, Salatiga 50711, Indonesia \\ Email: irwan@uksw.edu, indrastanti@yahoo.com, danu_netsoul@yahoo.com
}

\begin{abstract}
Abstrak:
Administrator suatu firewall ditantang untuk menyeimbangkan fleksibilitas dan keamanan saat merancang seperangkat aturan yang komprehensif. Firewall harus memberikan perlindungan terhadap malfeasants, sementara memungkinkan pengguna yang dipercaya untuk dapat terhubung. Sayangnya, tidak selalu mungkin untuk menyaring orang-orang jahat, karena penyaringan berdasarkan alamat IP dan port tidak membedakan pengguna yang terhubung. Orang-orang yang berniat jahat dapat berasal dari alamat IP terpercaya. Port terbuka tetap menjadi kerentanan: mereka mengizinkan koneksi untuk aplikasi tetapi juga dapat berubah menjadi pintu terbuka untuk serangan. Penelitian ini menyajikan suatu sistem keamanan baru, disebut port knocking, di mana pengguna terpercaya memanipulasi aturan firewall dengan mengirimkan informasi di seluruh port yang tertutup.
\end{abstract}

Keywords : port, knock, port knocking, iptables, firewall.

\section{Pendahuluan}

Komponen yang paling penting dalam membangun sebuah jaringan komputer yang aman adalah seputar firewall beserta celah-celah keamanan jaringan itu sendiri. Celah-celah keamanan dapat terbuka dikarenakan perangkat komputer tersebut diinstall dengan suatu program aplikasi seperti aplikasi pengolah dokumen, aplikasi email klien (client), aplikasi antivirus, aplikasi server klien, dan lain sebagainya yang mungkin dibutuhkan bahkan mungkin juga tidak dibutuhkan. Aplikasi-aplikasi yang diinstall tersebut, terutama yang terhubung dengan jaringan baik itu jaringan lokal maupun jaringan internet akan membuka port komunikasi. Port komunikasi tersebut merupakan port yang ada dalam protokol TCP atau UDP yang merupakan anggota dari transportation layer pada standar OSI. Melalui port komunikasi tersebut, jaringan internet atau jaringan di luar jaringan komputer dapat menjangkau perangkat komputer. Begitu pula sebaliknya, perangkat komputer lain yang membuka port komunikasi tertentu dapat 
dijangkau. Komunikasi dapat berjalan dengan lancar, pertukaran informasi menjadi mudah dan kenyamanan dalam berkomputer bertambah dengan terbukanya port komunikasi tersebut. Namun, kadang kala kenyamanan ini sering disalahgunakan oleh sebagian orang. Port komunikasi tersebut sering dijadikan sebagai celah untuk dimasuki secara ilegal. Port yang terbuka digunakan sebagai jalan menuju ke dalam jaringan internal atau ke server-server di dalamnya, kemudian mengacaukannya. Port komunikasi yang terbuka secara bebas tersebut juga bisa menjadi salah satu ancaman bagi keamanan data yang ada dalam sistem jaringan komputer. Sangat mungkin penyusup masuk ke dalam komputer, dan bahkan ke seluruh komputer di dalam jaringan komputer jika port tersebut dibiarkan terbuka secara bebas. Untuk itulah, firewall sangat dibutuhkan di dalam jaringan tersebut. Firewall memiliki tugas untuk melakukan pemblokiran terhadap port-port komunikasi yang terbuka di dalam sebuah jaringan komputer.

Di dalam firewall semua komunikasi yang keluar dan masuk dikontrol. Port yang tidak penting dapat diblokir (ditutup) dan port yang penting dan berbahaya juga dapat diblokir, sehingga hanya pihak yang diijinkan saja yang boleh masuk melalui port tersebut. Cara ini merupakan sistem pengamanan jaringan komputer yang paling efektif dan banyak digunakan. Akan tetapi terkadang pemblokiran yang dilakukan sering menjadi tidak fleksibel, ketika dibutuhkan untuk menjalin komunikasi dengan apa yang ada di dalam jaringan, firewall tidak mengijinkannya karena mungkin memang berada pada area yang tidak diijinkan. Padahal komunikasi yang ingin dilakukan sangatlah penting untuk kelancaran kerja. Misalnya melakukan koneksi dengan internet dan butuh mengakses web server melalui SSH untuk memperbaiki konfigurasinya, sementara port SSH pada server tersebut dilarang untuk diakses dari internet oleh firewall, tentu hal ini akan sangat merepotkan. Untuk menghindari hal-hal semacam ini, ada suatu metode yang sangat efektif yaitu dengan menggunakan metode port knocking. Port knocking adalah suatu metode untuk membangun komunikasi antar komputer dari mana pun selama masing-masing komputer tersebut terhubung dalam suatu jaringan komputer, dengan perangkat komputer yang tidak membuka port komunikasi apapun secara bebas, tetapi perangkat tersebut masih tetap dapat diakses dari luar, dengan menggunakan suatu format konfigurasi port ketukan yang berupa percobaan untuk mengirimkan koneksi pada port ketukan.

\section{Kajian Pustaka}

Port knocking adalah salah satu cara berkomunikasi pada jaringan komputer, cara yang digunakan adalah berkomunikasi melalui port yang tertutup [3]. Dedi Dwianto menjelaskan bahwa port knocking merupakan salah satu metode dalam keamanan jaringan komputer yang digunakan untuk membuka sebuah port yang tertutup atau membuka akses firewall dan mengijinkan knocker masuk melalui port yang dituju melalui pengiriman paket-paket tertentu ke port tujuan. Cara yang digunakan oleh Dedi Dwianto adalah dengan melakukan telnet ke port yang tertutup pada server dengan tujuan untuk membuka port yang dituju [1]. 


\section{Firewall dan Port Knocking \\ Format Ketukan}

Format ketukan yang digunakan dalam perancangan sistem adalah format port tunggal dengan pemetaan tetap, dan hanya menggunakan tiga port ketukan sebagai tujuan pengiriman paket data untuk melakukan ketukan.

Untuk mempermudah penentuan port ketukan, maka dibuat aturan pemilihan port ketukan sesuai dengan nomor port tujuan, digit terakhir pada nomor port ketukan merujuk pada nomor port tujuan [2]. Sebagai contoh, seorang user ingin mengakses port 22, dengan range port ketukan yang telah ditentukan yaitu antara port 2000 sampai dengan 4000, maka pemilihan port ketukan yang digunakan adalah seperti pada Gambar 1.

\begin{tabular}{|c|c|}
\hline Nomor port ketukan & Port tujuan \\
\hline $2000+\mathrm{a}, 3000+\mathrm{b}, 4000+\mathrm{c}$ & $\mathrm{abc}$ \\
\hline
\end{tabular}

Gambar 1. Penentuan Format Ketukan

Nomor port $2000+a, 3000+b, 4000+c$ merupakan nomor port tujuan pengiriman paket data yang berfungsi sebagai port ketukan. Nomor port ketukan menunjukkan port tujuan abc yang akan dibuka atau ditutup. Maka ketukan yang dilakukan oleh pengguna jika ingin membuka 22 adalah seperti pada Gambar 2.

$2000,3002,4002$

Gambar 2. Format Ketukan Untuk Membuka Port 22.

Sedangkan jika user ingin menutup port 22, maka ketukan yang dilakukan oleh pengguna adalah seperti pada Gambar 3.

$$
3002,4002,2000
$$

Gambar 3. Format Ketukan Untuk Menutup Port 22.

\section{Proses Ketukan Port}

Proses pengetukan port dilakukan dengan cara mengirimkan paket data dari alamat sumber menuju alamat tujuan. Header pada paket data tersebut akan diperiksa terutama 
header control list SYN yang digunakan untuk mensikronisasi sequence number. Apabila nomor port ketukan yang digunakan sebagai sequence ketukan sesuai dengan nomor port tujuan yang telah ditentukan sebagi nomor port ketukan, maka port yang dituju akan terbuka/tertutup sesuai dengan format ketukan yang digunakan, seperti ditunjukkan pada Gambar 4 dan Gambar 5.

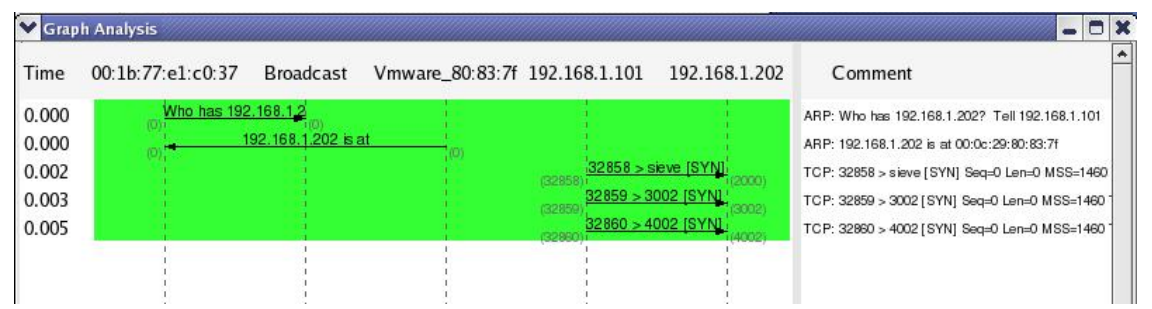

Gambar 4. Analisa Paket Data Saat Ketukan Pertama

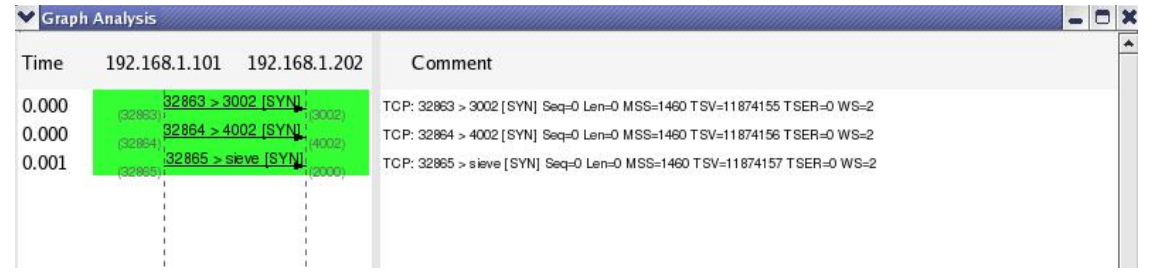

Gambar 5. Analisa Paket Data Saat Ketukan Kedua

\section{Implementasi Port Knocking pada Sistem Keamanan Jaringan Komputer}

\subsection{Instalasi Program}

Sebelum program port knocking dijalankan, pertama kali dilakukan instalasi program pada komputer server yang berfungsi untuk mendengarkan ketukan port dan pada komputer klien yang berfungsi untuk melakukan ketukan port terhadap komputer server.

Pada komputer server, instalasi dilakukan terhadap dua buah file, yaitu serverketuk.c dan list.c. Instalasi file pada komputer server juga membutuhkan sebuah library yang bernama Icap yang berfungsi untuk menangkap paket yang dikirimkan oleh komputer klien pada saat melakukan ketukan port. Perintah yang dilakukan pada instalasi ini ditunjukkan seperti pada Gambar 6. 


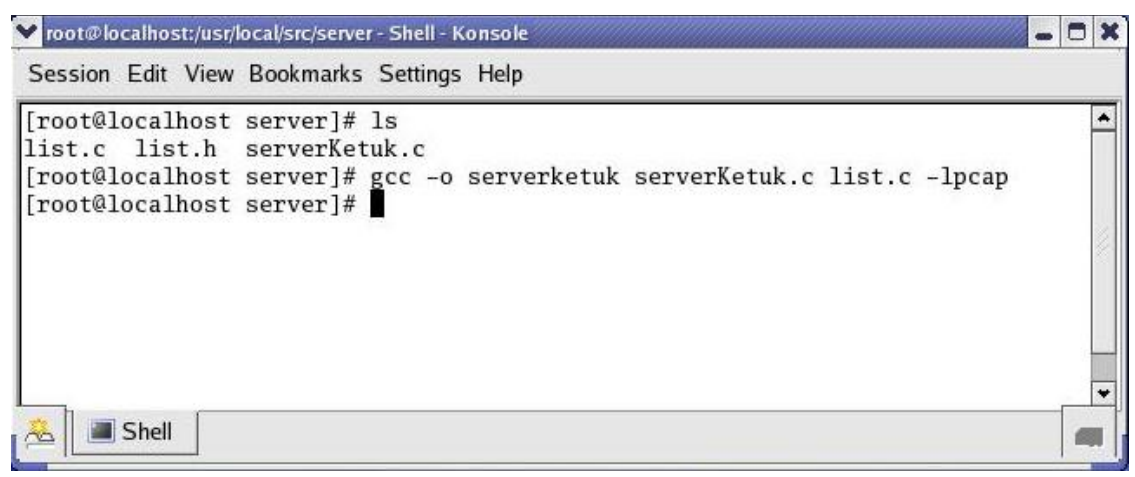

Gambar 6. Instalasi Serverketuk.

Hasil dari perintah yang ditunjukkan pada Gambar 6 adalah terciptanya sebuah file eksekusi yang bernama serverketuk. File serverketuk inilah yang nantinya akan dijalankan dan berfungsi untuk mendengarkan ketukan yang dilakukan oleh komputer klien, seperti terlihat pada Gambar 7.

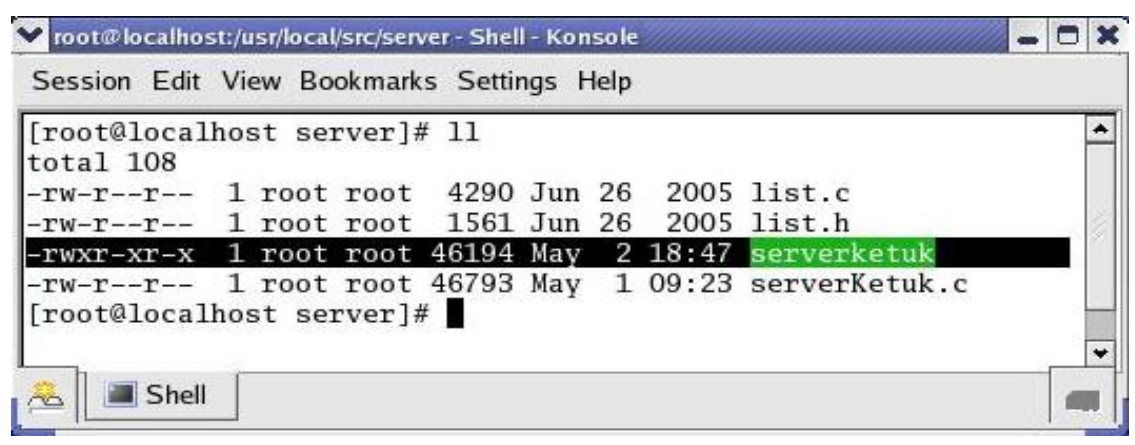

Gambar 7. File Serverketuk.

Sedangkan pada komputer klien, instalasi dilakukan terhadap dua buah file, yaitu ketukserver.c dan list.c. Instalasi file pada komputer klien tidak membutuhkan library khusus seperti pada saat melakukan instalasi file pada komputer server, karena program yang dijalankan pada komputer klien hanya berfungsi melakukan ketukan dengan cara mengirimkan paket ke port ketukan komputer server. Perintah yang dilakukan pada instalasi ini ditunjukkan seperti pada Gambar 8.

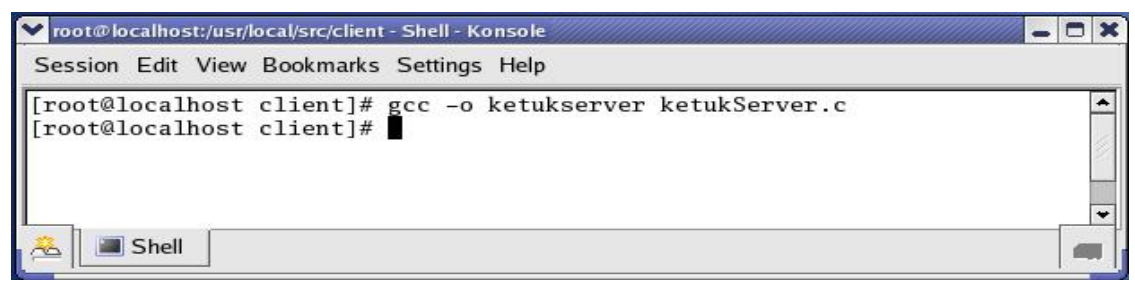

Gambar 8. Instalasi Ketukserver. 
Hasil dari perintah yang ditunjukkan pada Gambar 8 adalah terciptanya sebuah file eksekusi yang bernama ketukserver. File ketukserver ini berfungsi untuk melakukan ketukan port terhadap komputer server, seperti terlihat pada Gambar 9.

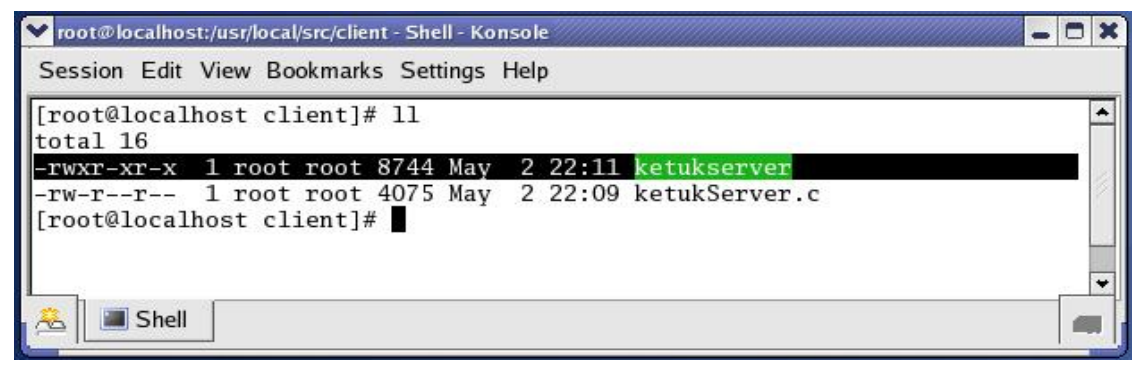

Gambar 9 File Ketukserver.

\subsection{Konfigurasi Program}

Setelah dilakukan kompilasi terhadap sourcecode server dan klien, maka perlu dilakukan konfigurasi agar komputer klien dapat melakukan ketukan dan pada komputer server dapat mendengarkan ketukan, maka dilakukan konfigurasi terlebih dahulu pada komputer server. Untuk melakukan konfigurasi, dibuat dua buah file yaitu file logketuk.log yang berfungsi untuk menyimpan log file yang berupa aktivitas yang terjadi pada server port knocking. File logketuk.log dibuat dan diletakkan pada direktori /var/log yang merupakan direktori pada sistem operasi Linux yang berfungsi untuk menyimpan log sistem operasi. Perintah untuk membuat file logketuk.log ditunjukkan seperti pada Gambar 10.

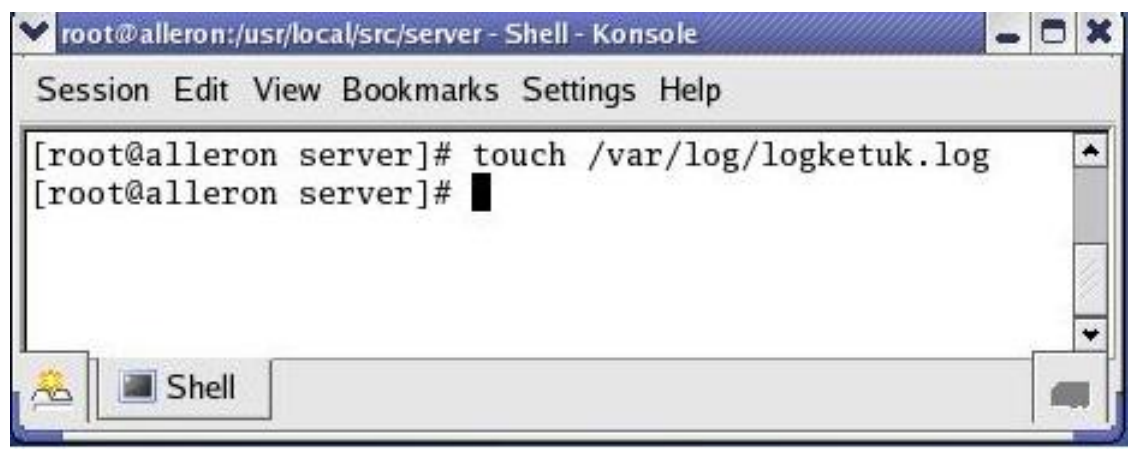

Gambar 10. Membuat File logketuk.log

File yang kedua yang perlu dibuat adalah configketuk.conf yang berfungsi untuk menentukan port ketukan dan menentukan perintah iptables yang berfungsi sebagai firewall dan digunakan untuk membuka atau menutup port tujuan. File configketuk.conf dibuat dan diletakkan pada direktori letc yang merupakan direktori pada sistem operasi Linux yang berfungsi untuk menampung file-file konfigurasi sistem. perintah untuk membuat file configketuk.conf ditunjukkan seperti pada Gambar 11. 


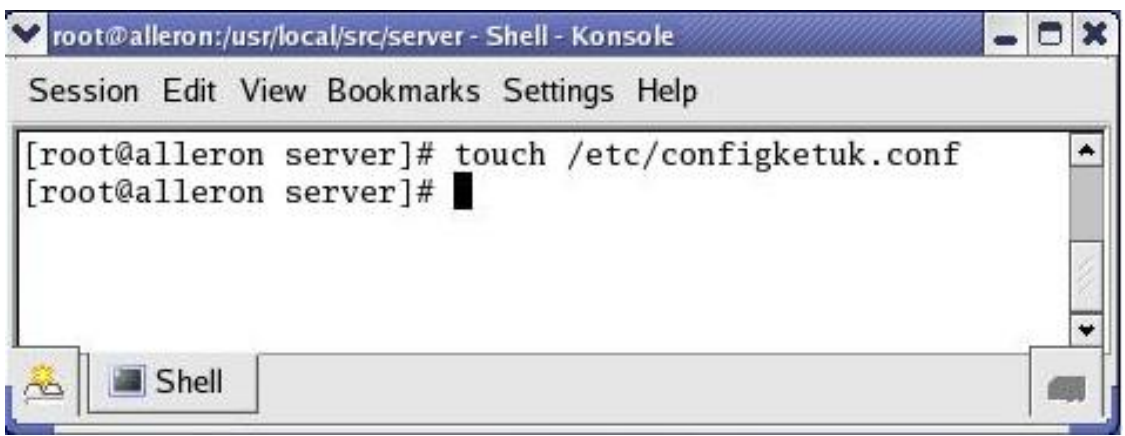

Gambar 11. Membuat File configketuk.conf

Setelah tercipta file configketuk.conf, maka langkah selanjutnya adalah mengisi file configketuk.conf tersebut dengan beberapa baris text konfigurasi. Isi dari file konfigketuk.conf ditunjukkan seperti pada Gambar 12.

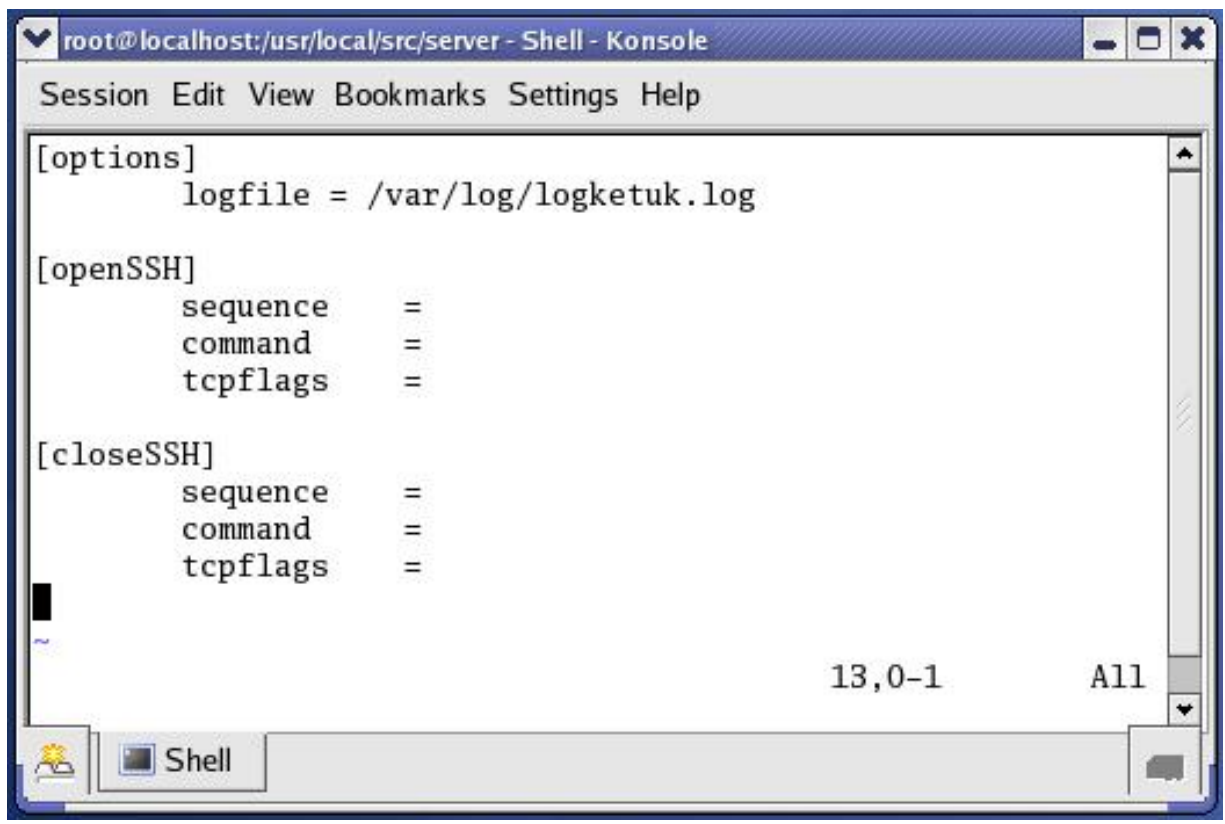

Gambar 12. Isi File configketuk.conf.

Terdapat tiga bagian utama pada file configketuk.conf, yaitu:

Bagian pertama adalah bagian options yang merupakan bagian yang berfungsi untuk menunjukkan letak file log yang berfungsi untuk mencatat semua aktivitas ketukan.

Bagian kedua adalah bagian bukaPort yang merupakan bagian yang digunakan sebagai konfigurasi untuk membuka port tujuan. Pada bagian bukaPort terdapat tiga buah baris perintah, yaitu: 
- Sequence : berfungsi untuk menentukan port ketukan yang digunakan untuk membuka port tujuan.

- Command : berfungsi untuk menentukan perintah iptables yang dijalankan, yaitu perintah untuk membuka port tujuan jika terjadi ketukan pada port ketukan.

- Tcpflags : menunjukkan header paket yang dikirimkan sebagai ketukan port.

Bagian ketiga adalah bagian tutup port yang digunakan sebagai konfigurasi untuk menutup kembali port tujuan. Pada bagian tutupPort terdapat tiga buah konfigurasi, yaitu:

- Sequence : berfungsi untuk menentukan port ketukan yang digunakan untuk menutup port tujuan.

- Command : berfungsi untuk menentukan perintah iptables yang dijalankan, yaitu perintah untuk menutup port tujuan jika terjadi ketukan pada port ketukan.

- Tcpflags : menunjukkan header paket yang dikirimkan sebagai ketukan port.

Untuk menentukan port ketukan, maka ditambahkan baris perintah pada file konfigketuk.conf, seperti ditunjukkan pada Gambar 13.

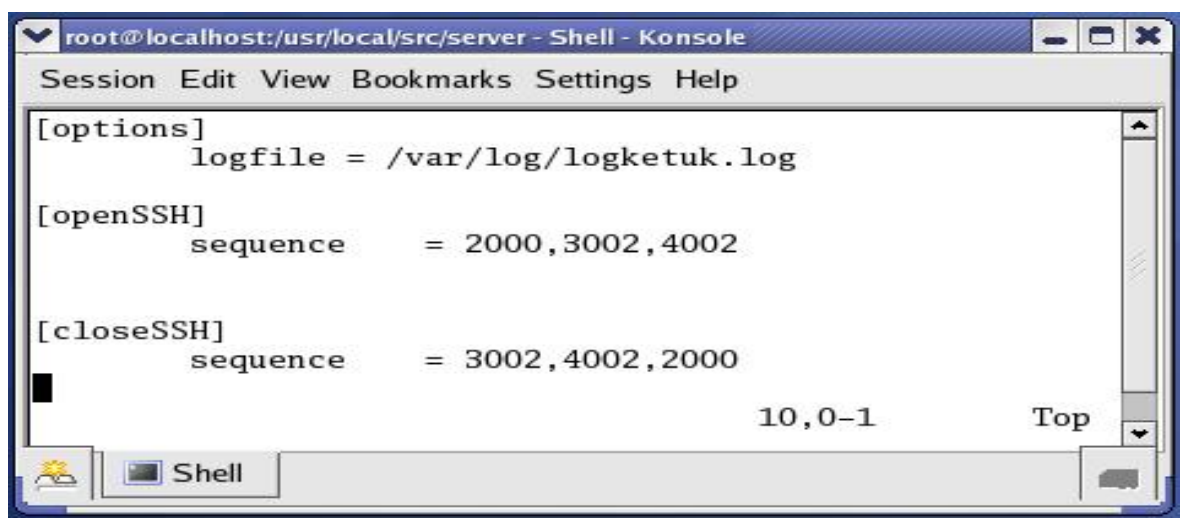

Gambar 13. Format Ketukan File configketuk.conf.

Pada bagian bukaSSH ditentukan tiga nomor port ketukan, yaitu port 2000, port 3002, dan port 4002. Jika terjadi ketukan terhadap ketiga port tersebut secara berurutan, maka server akan membuka port tujuan sesuai dengan perintah iptables yang ditentukan.

Pada bagian tutupSSH ditentukan tiga nomor port ketukan, yaitu port 3002, port 4002, dan port 2000. Jika terjadi ketukan terhadap ketiga port tersebut secara berurutan, maka server akan menutup port tujuan sesuai dengan perintah iptables yang ditentukan.

Untuk menentukan perintah iptables yang akan dijalankan jika terjadi ketukan port, maka ditambahkan baris perintah pada file konfigketuk.conf, seperti ditunjukkan pada Gambar 14. 


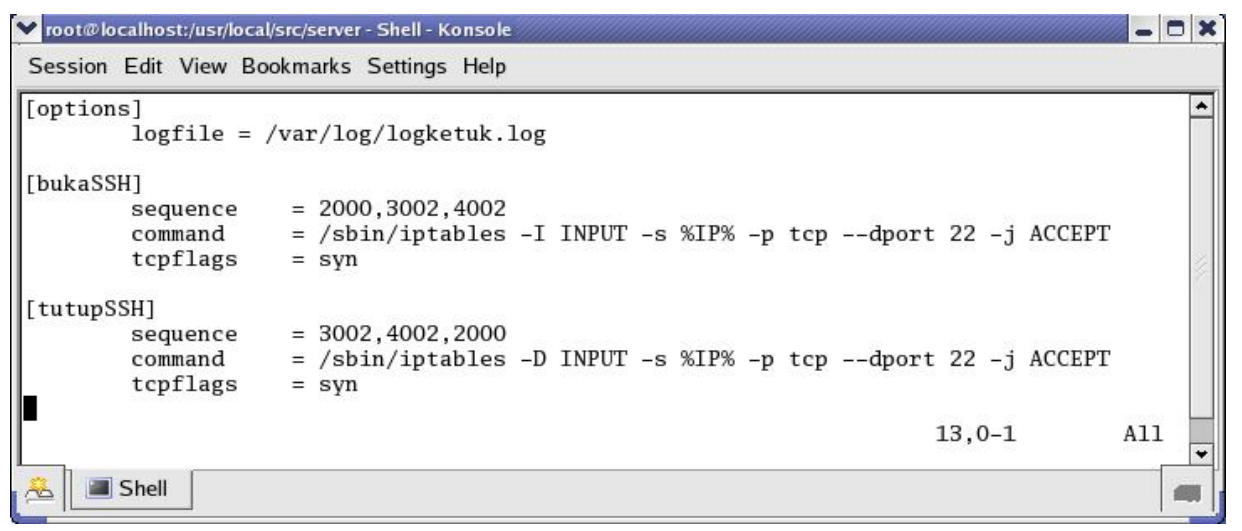

Gambar 14. Perintah iptables File configketuk.conf.

Pada bagian bukaSSH, perintah iptables yang dijalankan ketika terjadi ketukan pada port 2000 , port 3002 , dan port 4002 , adalah perintah yang bertujuan untuk mengubah aturan iptables,yaitu dengan membuka akses terhadap alamat IP komputer klien agar dapat mengakses port 22 pada komputer server.

Pada bagian tutupSSH, perintah iptables yang dijalankan ketika terjadi ketukan pada port 3002, port 4002, dan port 2000, adalah perintah yang bertujuan untuk mengubah aturan iptables, yaitu dengan menutup kembali akses terhadap alamat IP komputer klien sehingga tidak lagi dapat mengakses port 22 pada komputer server.

\subsection{Penerapan Program Pada Sistem Keamanan Jaringan Komputer}

Setelah dilakukan konfigurasi pada file configketuk.conf, maka dilakukan implementasi pada sistem jaringan komputer. Implementasi dilakukan pada dua buah komputer yang saling terhubung pada jaringan komputer. Topologi jaringan komputer yang digunakan sebagai implementasi sistem dapat dilihat pada Gambar 15.

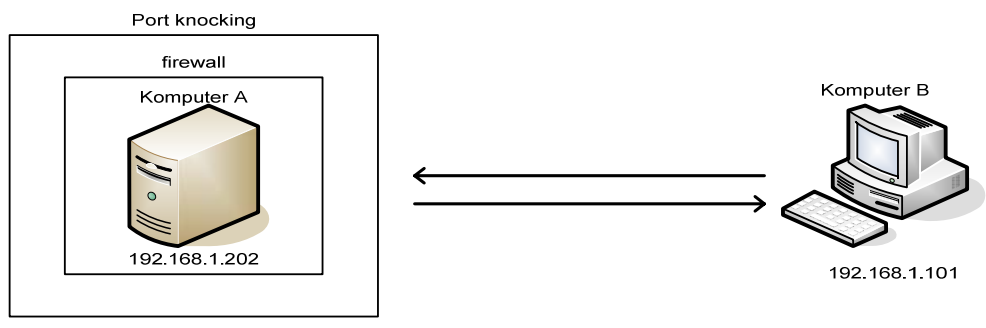

Gambar 15. Topologi Jaringan Saat Implementasi Sistem.

Pada Gambar 15, komputer A memiliki alamat IP 192.168.1.202 dan berfungsi sebagai server port knocking yang bertugas untuk menyediakan layanan port knocking, 
sedangkan komputer B memiliki alamat IP 192.168.1.101 dan berfungsi sebagai klien yang bertugas untuk melakukan ketukan ke komputer server.

Langkah pertama dalam implementasi program adalah menutup semua port yang ada pada komputer $A$ dengan menggunakan perintah iptables yang bertujuan agar semua paket yang menuju komputer $A$ akan langsung dibuang (DROP) sehingga komputer $A$ tidak dapat diakses dari komputer lain. Perintah yang digunakan untuk menutup semua port yang ada pada komputer A ditunjukkan seperti pada Gambar 16.

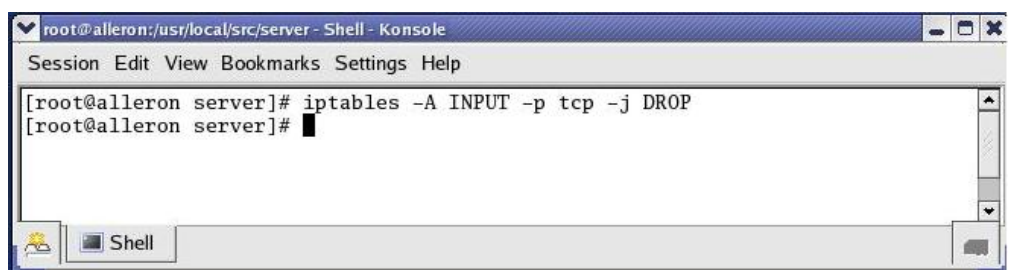

Gambar 16. Perintah iptables Untuk Menutup Semua Port Pada Protokol TCP

Hasil dari Gambar 16 adalah tertutupnya semua port pada komputer A yang berarti bahwa tidak ada jalan masuk yang terbuka pada komputer A yang bisa diakses oleh komputer lain, seperti terlihat pada Gambar 17. Hal ini dibuktikan dengan melakukan scanning port menggunakan Nmap pada komputer A, seperti terlihat pada Gambar 17.

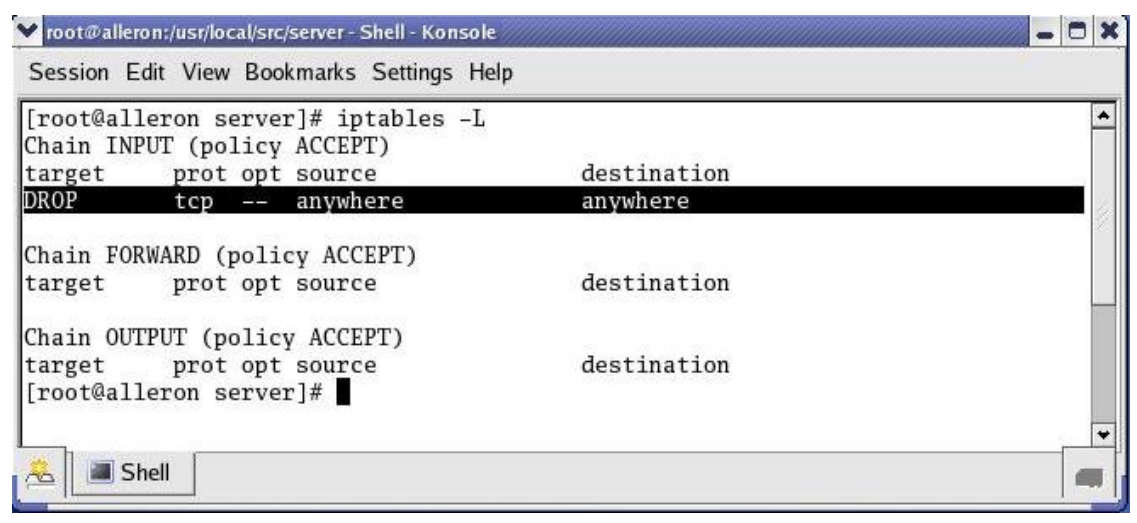

Gambar 17. Chain iptables Setelah Semua Port Pada Protokol TCP Ditutup.

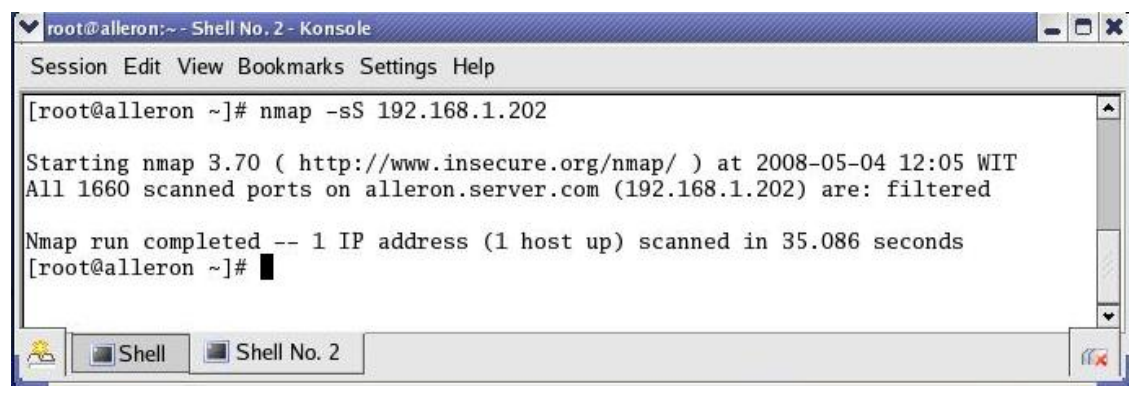

Gambar 18. Hasil Scanning Port Setelah Semua Port Pada Protokol TCP Ditutup. 
Langkah kedua adalah melakukan konfigurasi pada file configketuk.conf. Konfigurasi yang dilakukan pada file configketuk.conf antara lain adalah: Menentukan format port ketukan untuk membuka port 22 (port SSH). Menentukan aturan iptables yang berfungsi untuk membuka port 22 (port SSH) dan mengijinkan alamat IP sumber yang melakukan ketukan port untuk mengakses port 22 (port SSH) jika terjadi ketukan pada port 2000,3002,4002, seperti terlihat pada Gambar 19.

command $\quad=/$ sbin/iptables -I INPUT -s \%IP\% -p tcp --dport 22 -j ACCEPT

Gambar 19. Perintah iptables Untuk Membuka Port 22

Menentukan format port ketukan untuk menutup kembali port 22 (port SSH), seperti terlihat pada Gambar 20.

$$
\begin{array}{r}
\text { [tutupSSH] } \\
\text { sequence }
\end{array}=3002,4002,2000
$$

Gambar 20. Format Ketukan Untuk Menutup Kembali Port 22

Menentukan aturan iptables yang berfungsi untuk menutup kembali port 22 (port SSH) dan tidak mengijinkan kepada alamat IP manapun juga untuk mengakses port 22 (port SSH) jika terjadi ketukan pada port 3002,4002,2000, seperti terlihat pada Gambar 21.

$$
\text { command } \quad=/ \text { sbin/iptables }-D \text { INPUT }-s \text { \%IP\% }-p \text { tcp --dport } 22-j \text { ACCEPT }
$$

Gambar 21. Perintah iptables Untuk Menutup Kembali Port 22

Secara keseluruhan isi dari file configketuk.conf adalah seperti terlihat pada Gambar 22.

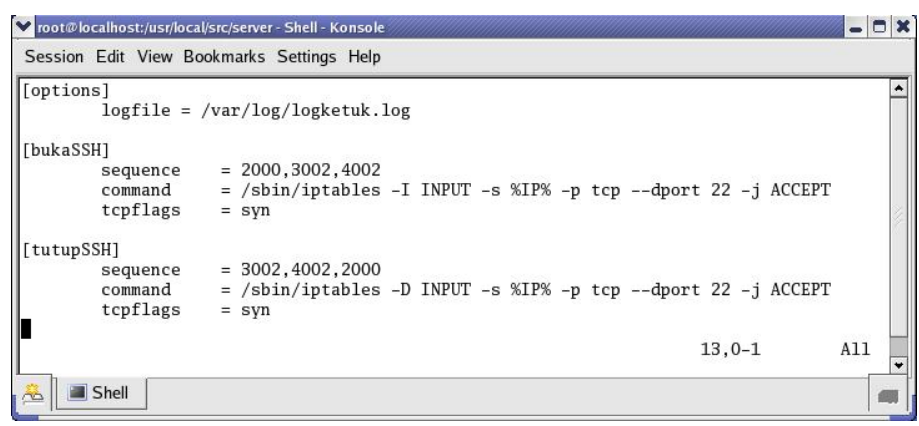

Gambar 22. Konfigurasi File configketuk.conf Untuk Membuka dan Menutup Port 22 
Langkah ketiga adalah menjalankan file serverketuk pada komputer A. Perintah yang digunakan adalah seperti terlihat pada Gambar 23.

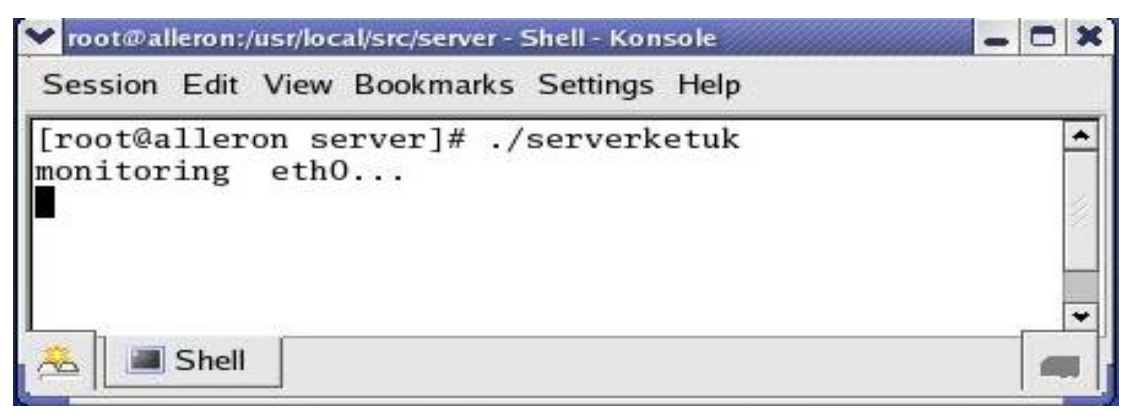

Gambar 23. Perintah Untuk Menjalankan Program serverketuk.

Langkah keempat adalah menjalankan program ketukserver pada komputer B yang berfungsi untuk melakukan pengetukan port oleh komputer B ke komputer A pada port 2000,3002,4002 dengan tujuan agar komputer A membuka port 22 dan memberikan ijin agar komputer B dapat mengakses port 22 pada komputer A. Perintah yang digunakan adalah seperti terlihat pada Gambar 24.

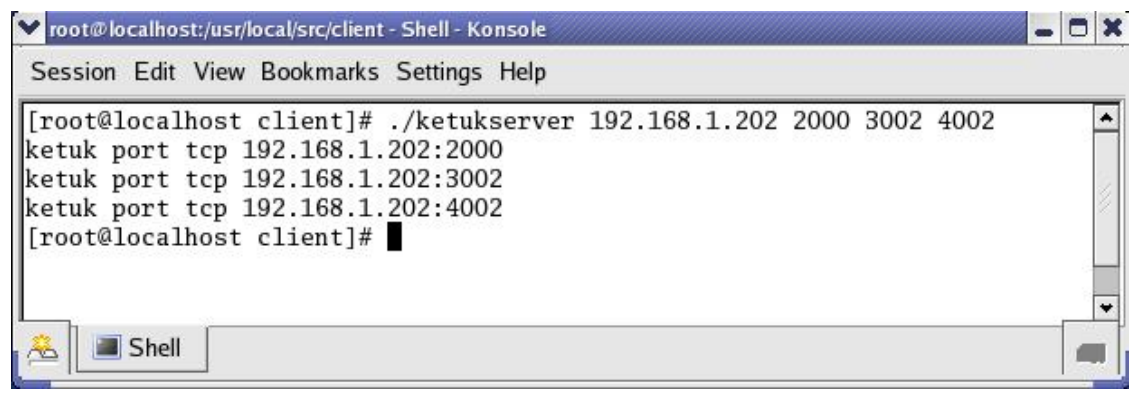

Gambar 24. Menjalankan Program ketukserver Untuk Membuka Port 22.

Setelah komputer B melakukan ketukan port 2000, 3002, 4002 pada komputer A, maka pada komputer A akan melakukan monitoring port apakah port yang diketuk sesuai dengan format port ketukan bukaSSH, seperti terlihat pada Gambar 25. 


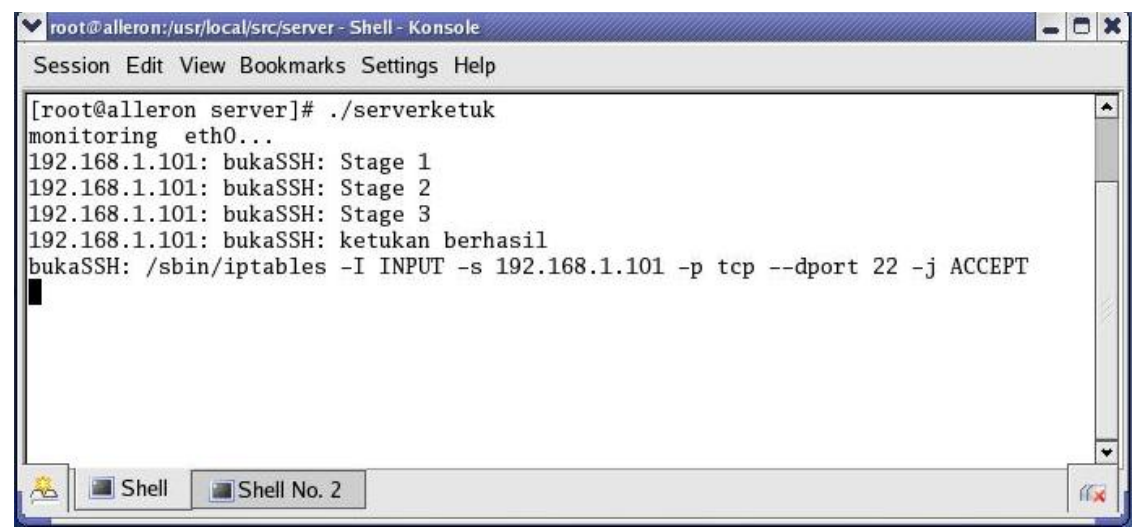

Gambar 25. Monitoring Port yang Dilakukan Oleh serverketuk Setelah Ketukan bukaSSH

Pada Gambar 26, jika ketukan yang dilakukan oleh komputer B sesuai dengan format ketukan bukaSSH, maka program serverketuk pada komputer $A$ akan menjalankan perintah iptables untuk membuka port 22 (port SSH) pada komputer A dan hanya akan memberikan akses kepada komputer B untuk menggunakan port 22 (port SSH) tersebut.

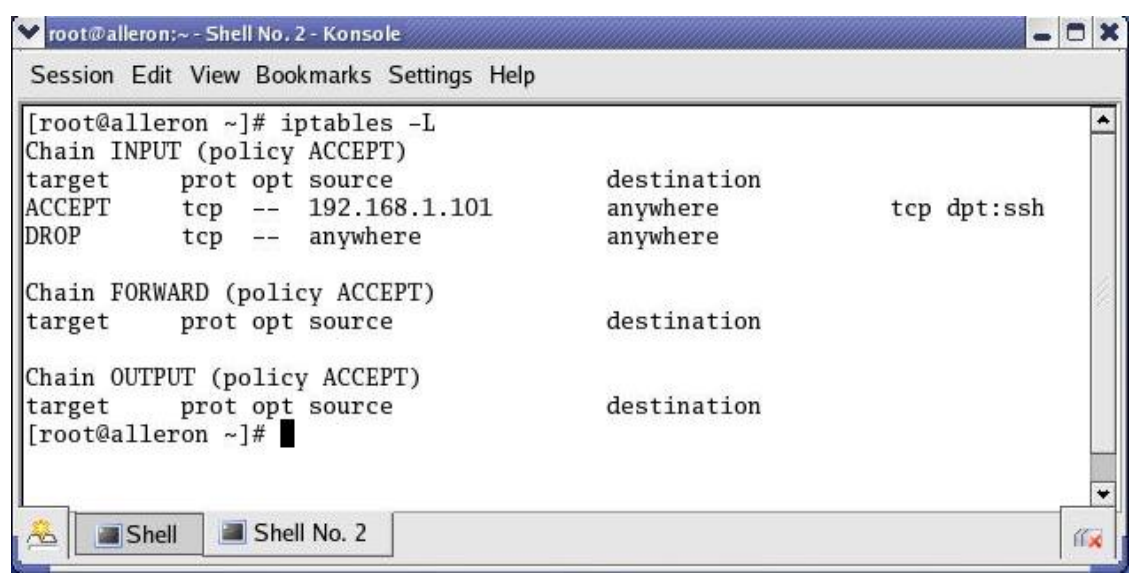

Gambar 26. Chain iptables Setelah Terjadi Ketukan Untuk Membuka Port 22

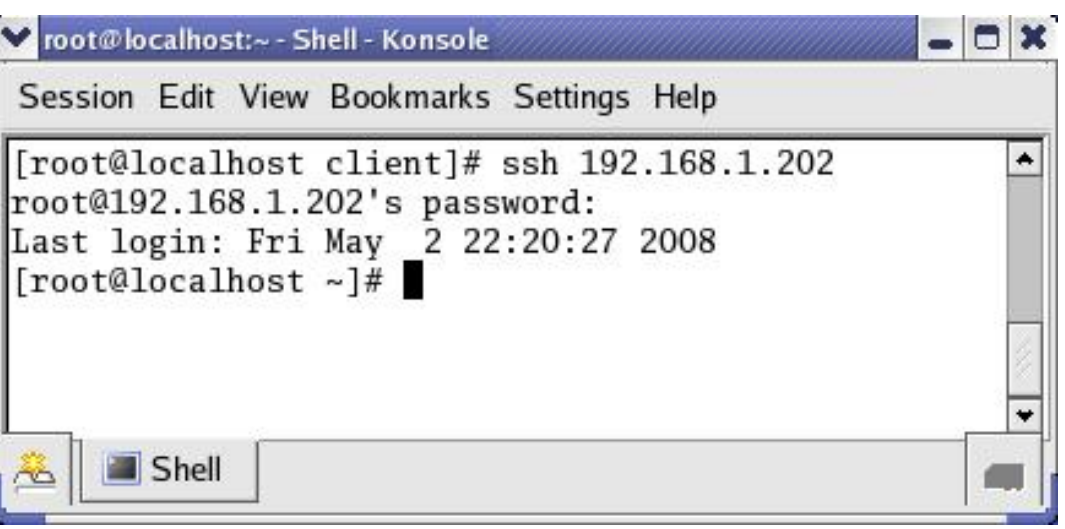

Gambar 27. Akses yang Dilakukan Klien ke Port 22 yang Telah Terbuka 
Pada Gambar 27, komputer B melakukan koneksi SSH ke komputer A, setelah komputer B melakukan ketukan port, dan komputer A membuka port 22 hanya untuk diakses oleh komputer $\mathrm{B}$.

Setelah komputer B selesai mengakses port 22 (port SSH) pada komputer A, maka langkah kelima yang dilakukan adalah komputer B melakukan ketukan port kembali dengan format ketukan yang digunakan untuk menutup kembali port 22 (port SSH) pada komputer A, ketukan yang dilakukan adalah ketukan terhadap port 3002, 4002, 2000. Perintah yang digunakan adalah seperti pada Gambar 28.

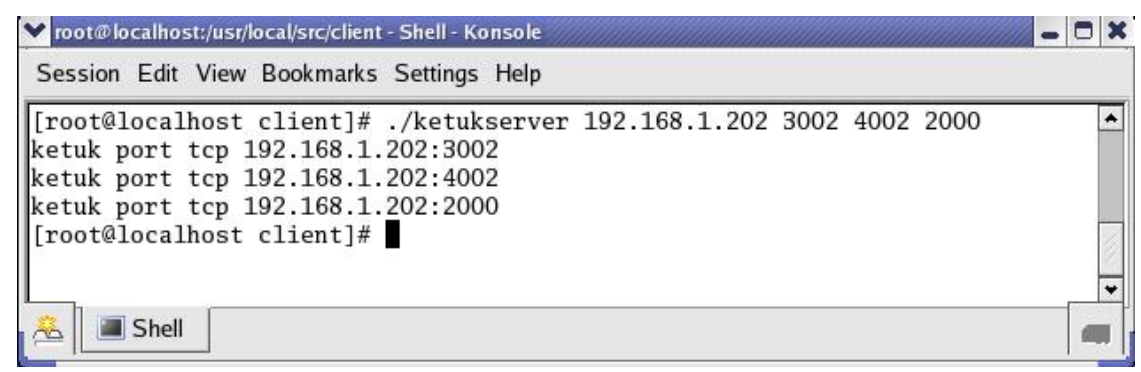

Gambar 28. Menjalankan Program ketukserver Untuk Menutup Kembali Port 22

Ketika komputer B melakukan ketukan port 3002, 4002, 2000 pada komputer A, maka program serverketuk akan melakukan monitoring port apakah port yang diketuk sesuai dengan format port ketukan tutupSSH. Jika ketukan tersebut benar, maka program serverketuk akan menjalankan perintah iptables untuk menutup kembali port 22 (port SSH) pada komputer $A$, sehingga tidak ada satupun komputer termasuk juga komputer $B$ yang dapat mengakses kembali port 22 pada komputer A, seperti ditunjukkan pada Gambar 29 dan Gambar 30.

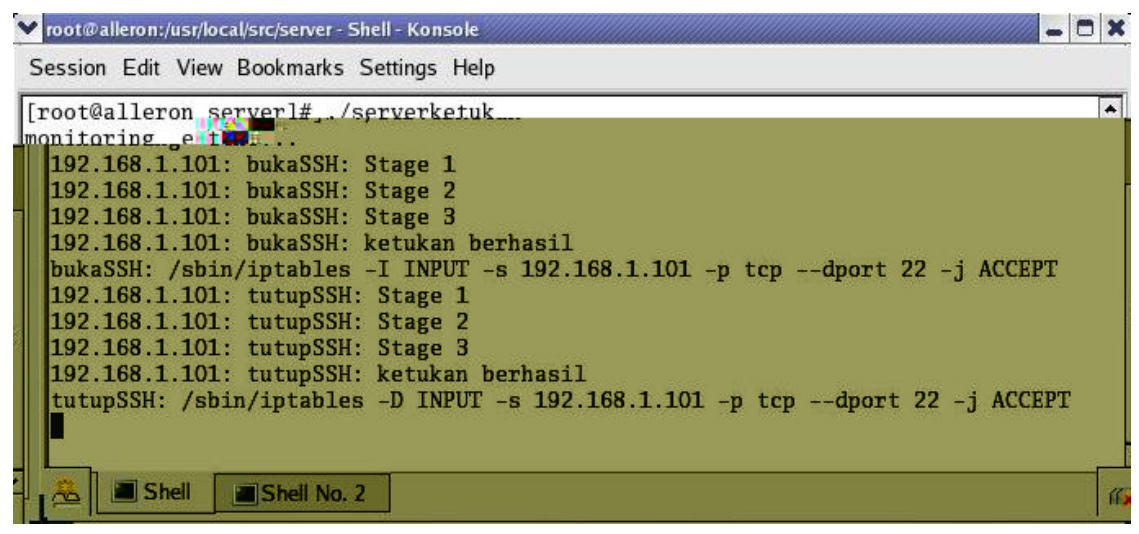

Gambar 29. Monitoring serverketuk Setelah Terjadi Ketukan tutupSSH. 


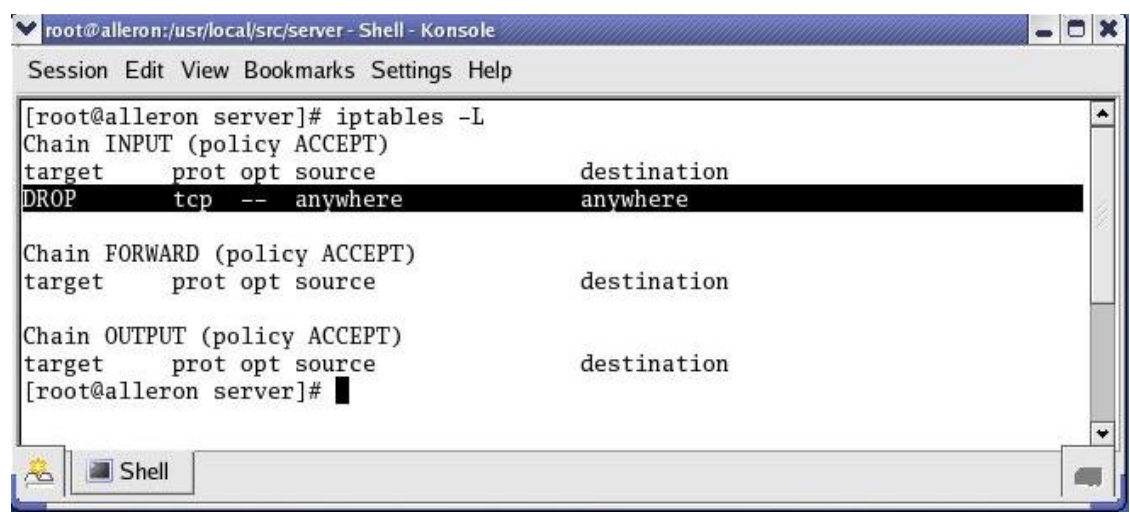

Gambar 30. Chain iptables Setelah Terjadi Ketukan tutupSSH

\section{Penutup}

1. Metode port knocking sangat berguna diterapkan pada sistem keamanan jaringan komputer.

2. Metode port knocking sangat berguna bagi administrator jaringan atau server yang harus mengurusi jaringan atau server secara terus menerus dari mana saja, karena port knocking aman digunakan untuk membuat komunikasi antar komputer pada jaringan komputer.

3. Dengan metode port knocking, komunikasi antar komputer dapat dilakukan meskipun melalui port yang tertutup.

4. Metode port knocking cukup baik diimplementasikan pada jaringan yang lalu lintasnya tidak terlalu padat, karena pada jalur lalu lintas jaringan yang padat, port yang digunakan sebagai komunikasi harus terbuka dan di akses secara terus menerus.

5. Dengan metode port knocking orang lain yang tidak berhak tidak mampu mengetahui apakah ada port yang terbuka dan memberikan layanan.

\section{Daftar Pustaka}

[1] Dwianto, D. (2007). Membuka akses firewall melalui Networks. echo|zine, volume 5 issue 7. Diambil dari: http://ezine.echo.or.id/ezine17/09.txt.

[2] Jeanquier, S. (2006). An analysis of port knocking and single packet authorization. Information Security Group : Royal Holloway College, University of London.

[3] Krzywinski, M. (Jun 16, 2003). Port knocking. Linux Journal. Diambil dari: http://www.linuxjournal.com/article/6811. 